\title{
Research Article \\ Effects of Density and Moisture Variation on Dynamic Deformation Properties of Compacted Lateritic Soil
}

\author{
Weizheng Liu, ${ }^{1}$ Shuai Qu, ${ }^{1}$ Zhihong Nie, ${ }^{1}$ and Junhui Zhang ${ }^{2}$ \\ ${ }^{1}$ School of Civil Engineering, Central South University, Changsha 410075, China \\ ${ }^{2}$ School of Traffic and Transportation Engineering, Changsha University of Science \& Technology, Changsha 410114, China \\ Correspondence should be addressed to Zhihong Nie; niezhih@126.com
}

Received 8 December 2015; Accepted 17 February 2016

Academic Editor: Philip Eisenlohr

Copyright (c) 2016 Weizheng Liu et al. This is an open access article distributed under the Creative Commons Attribution License, which permits unrestricted use, distribution, and reproduction in any medium, provided the original work is properly cited.

\begin{abstract}
A series of repeated load triaxial tests were conducted in this study to investigate the influences of compaction density and postcompaction moisture variation on the dynamic elastic modulus $\left(E_{d}\right)$ and plastic permanent strain (PPS) of compacted lateritic soil. Specimens were compacted at optimum moisture content (OMC) and three degrees of compaction (90\%, 93\%, and 96\%). Then the specimens were dried or wetted to different moisture contents (OMC, OMC $\pm 3 \%, \mathrm{OMC} \pm 6 \%$, and $\mathrm{OMC}+9 \%$ ) prior to testing for $E_{d}$ and PPS. Results show that moisture content has greater influence on the $E_{d}$ and PSS than compaction degree, and the increase in moisture content leads to a decrease of $E_{d}$ and an increase of PPS. Furthermore, an empirical relationship between $E_{d}$ and applied cyclic stress $\left(\sigma_{d}\right)$ is developed that incorporates density and moisture variations. Three different evolution types of PPS with number of load cycles, plastic stable, plastic creep, and incremental collapse, are identified as the increase of moisture content. In addition, the critical dynamic stress $\left(\sigma_{d c}\right)$ separating stable and unstable deformation is determined based on the shakedown concept. The envelope curves of $\sigma_{d c}$-moisture of lateritic soil with different degrees of compaction are also determined to provide reference for the pavement design.
\end{abstract}

\section{Introduction}

In the field construction, subgrade soils are generally compacted at or near optimum moisture content (OMC) and maximum dry density (MDD), and as such the compacted subgrade is usually present in an unsaturated condition. However, during the service life of a subgrade, the moisture content at the time of compaction is not constant and firstly changes to an equilibrium water content (EPC) and then fluctuates along the EPC due to the seasonal environmental factors such as groundwater table variation, rainwater infiltration, and evaporation [1-5]. Several recent studies have shown that variations in moisture content significantly degrade the engineering properties of compacted subgrade [6-9] and contribute to the deterioration and premature failure of pavements. It is evident that proper consideration to the effect of moisture variation should be given in realistic pavement design and analysis.

Lateritic soils are widely distributed in tropical and subtropical regions such as south China, in which lateritic soils are extensively used as fill materials for the subgrade construction of highway and railway due to the expanding urbanization and deficiency in good quality crushed aggregate. Nevertheless, lateritic soils possess special properties with high plasticity and high water sensitivity [10], which can lead to significant moisture variation of compacted subgrade with the seasonal environmental factors. Considerable studies have been carried out on the effect of moisture variation on the shear strength and static modulus of lateritic soil [1115]. It was observed that an increase in moisture content typically decreased the matric suction and hence decreased the shear strength and static modulus. Although dynamic deformation properties including resilient stiffness and accumulated permanent deformation are closely related to the service performance of operated subgrade, particularly under high-speed and heavy-axle traffic loading, limited research work has been performed on dynamic elastic modulus $\left(E_{d}\right)$ and plastic permanent strain (PPS) of lateritic soil. Fall et al. [16] investigated the evolution of permanent and reversible deformation of the three laterites under various cyclic stress 
levels. Samb et al. [17] indicated that the moisture content seemed to affect the values of the resilient modulus in a sensitive way. Parreira and Gonçalves [18] and Mu et al. [19] found that resilient modulus decreased as the increase of moisture content and there was often a strong correlation between matric suction and resilient modulus. Through varying moisture contents at compaction, Liao et al. [20], Liu et al. [21], and Zhang et al. [22] evaluated the effect of moisture variation on the critical dynamic stress. However, it should be pointed out that laboratory specimens compacted at different moisture contents cannot accurately simulate the field conditions, in which subgrades were compacted at unique moisture content and then subjected to postcompaction moisture changes. Few studies have addressed the variations of dynamic elastic modulus and plastic permanent deformation of compacted lateritic soil with postcompaction moisture contents.

Compaction degree, $k$, defined as the ratio of dry density of the field compaction to laboratory maximum dry density, is a key parameter for ensuring the proper performance of a subgrade and is also an important factor influencing the development of permanent deformations [23-25]. Barksdale [23] observed an increase of permanent axial strain of about $185 \%$ when the granular material was compacted at $95 \%$ instead of $100 \%$ of maximum compaction density. However, the effect of density on $E_{d}$ and PPS of fine grained soils such as lateritic soil has not been clearly observed.

The primary objective of this study is to address the variations of $E_{d}$, PPS, and critical dynamic stress $\left(\sigma_{d c}\right)$ with postcompaction moisture contents and compaction density for compacted lateritic soil. Specimens are compacted at OMC and three degrees of compaction (90\%, 93\%, and 96\%) and then subjected to wetted or dried procedures and six levels of moisture contents (OMC, OMC $\pm 3 \%$, OMC $\pm 6 \%$, and $\mathrm{OMC}+9 \%$ ) are selected for repeated load triaxial tests. An empirical relationship between $E_{d}$ and applied cyclic deviator stress $\left(\sigma_{d}\right)$ is developed that incorporates density and moisture variations. Furthermore, based on the shakedown concept, the envelope curves of $\sigma_{d c}$ moisture of lateritic soil with different compaction degrees are presented.

\section{Materials and Specimen Preparation}

2.1. Materials. Residual lateritic soil sampled from Jiangxi Province, frequently encountered subgrade soil in the construction of highways in southern China, was selected for testing in this study. Specific gravity, Atterberg limits, wet sieve and hydrometer analysis, and compaction characteristics were performed on the tested soil. A summary of the test results is presented in Table 1 . The liquid limit and plasticity index of the soil are $45 \%$ and 20 , respectively. The silt content and clay content are $28.9 \%$ and $55.2 \%$, respectively. This soil was classified as A-7-5 according to AASHTO classification method and as CL as per unified soil classification system (USCS). The results of MDD and OMC obtained from the standard Proctor compaction test are used to establish compaction conditions for the repeated load triaxial tests.
TABle 1: Properties of tested soil.

\begin{tabular}{lc}
\hline Property & Lateritic soil \\
\hline Specific gravity & 2.70 \\
Liquid limit (LL, \%) & 45 \\
Plasticity index (PI) & 20 \\
Sand (>0.075 mm, \%) & 15.9 \\
Silt $(0.005 \mathrm{~mm}$ to 0.075 mm, \%) & 28.9 \\
Clay (<0.005 mm, \%) & 55.2 \\
AASHTO classification & $\mathrm{A}-7-5$ \\
USCS classification & $\mathrm{CL}$ \\
Maximum dry density, MDD $\left(\mathrm{kN} / \mathrm{m}^{3}\right)$ & 17.8 \\
Optimum moisture content, OMC $(\%)$ & 18.0 \\
\hline
\end{tabular}

2.2. Specimen Preparation. Prior to specimen preparation, bulk soil samples were subjected to air drying. The dry soil was first processed through a $2.00 \mathrm{~mm}$ sieve and then thoroughly mixed with the desired amount of deaired water to achieve the optimum moisture content, and the wet soil mixture was left in an airtight container overnight to achieve homogenous moisture conditions.

Three degrees of compaction (90\%, 93\%, and 96\%) were selected to prepare specimens for triaxial tests. The cylindrical specimens with $50 \mathrm{~mm}$ in diameter and $100 \mathrm{~mm}$ in height were compacted in a rigid split mold and in three layers of equal weight using a Proctor hammer. After compaction, the cylindrical specimen was extracted from the split mold and the initial weight, height, and diameter were measured.

In order to simulate different stages of the in-service subgrade exposure to seasonal environmental conditions, the specimens firstly compacted at optimum moisture content were then subjected to drying or wetting procedures. This process of varying moisture contents under the same initial condition was followed to minimize fabric effects on the subsequent test results. This is because the change in compaction moisture content affects the soil structure [6]. Six levels of moisture contents, dry side (OMC $-3 \%$ and $\mathrm{OMC}-6 \%$ ), optimum (OMC), and wet side (OMC $+3 \%$, $\mathrm{OMC}+6 \%$, and $\mathrm{OMC}+9 \%$ ), were selected to address variation of postcompaction moisture content. The selected range of moisture content deviating from $\mathrm{OMC}$ is generally consistent with results from field monitoring research undertaken by Thang et al. [3] and Taamneh and Liang [26].

Air-drying, carried out inside a temperature controlled laboratory to ensure constant condition, was employed as the drying procedure to achieve different moisture contents lower than OMC. Specimens were subjected to drying procedure, while the specimen mass was continuously measured. As soon as the specimen reached the target mass (and hence target water content), it was wrapped in a cling film for three days, which is sufficient to achieve uniformity distribution of moisture in the specimens.

The procedure used to increase the water content of sample was a more laborious system compared to the drying procedure. According to the procedure developed by Mendes [27], the wetting process was performed by using minifoggers. After wetting to achieve the target water content, the 
TABle 2: Parameters for $E_{d}$ and PPS test.

\begin{tabular}{lcccc}
\hline $\begin{array}{l}\text { Compaction } \\
\text { degree, } k\end{array}$ & $\begin{array}{c}\text { Moisture content, } \\
w\end{array}$ & $\begin{array}{c}\text { Confining } \\
\text { pressure, } \sigma_{c}(\mathrm{kPa})\end{array}$ & $\begin{array}{c}\text { Static deviator } \\
\text { stress, } \sigma_{s}(\mathrm{kPa})\end{array}$ & $\begin{array}{c}\text { Dynamic deviator load (N) } \\
\text { Multistage loading } \\
\text { sequence for } E_{d}\end{array}$ \\
\hline $90 \%$ & $12 \%, 15 \%, 18 \%$, & 60 & 30 & $\begin{array}{c}\text { Single-stage } \\
\text { loading sequence } \\
\text { for PPS }\end{array}$ \\
$93 \%$ & $21 \%, 24 \%, 27 \%$ & & $90,105,120,135$, \\
$96 \%$ & & & $150,60,75$, \\
\hline
\end{tabular}

specimens were also wrapped in a cling film for three days to assure homogenization of the water content within the soil. Mendes [27] verified that this method can wet the samples homogeneously and uniformly.

\section{Test Methods and Procedures}

A DDS-70 cyclic triaxial test apparatus with electromagnetic control system was used to perform $E_{d}$ and PPS tests on the specimens. Two externally mounted linear variable differential transducers (LVDTs), directly connected to the data acquisition system, were used to measure the axial displacements of the soil sample. The maximum scale stroke for these two LVDTs is $\pm 10 \mathrm{~mm}$, with a resolution accuracy of $0.001 \mathrm{~mm}$.

The $E_{d}$ and PPS tests were conducted in accordance with the SL237-032 [28] test methods. To simulate the slow drainage relative to the traffic loading duration, the tests were carried out under undrained conditions. Compressed air was used to apply confining pressure to the specimens. The effect of confining pressure on $E_{d}$ and PPS properties was ignored in this study and a constant confining pressure of $60 \mathrm{kPa}$ was applied to represent the in situ effective consolidation pressures. Moreover, to stimulate the nonisotropic consolidation state due to the pavement loading, an initial static deviator stress of $30 \mathrm{kPa}$ was applied to the specimen. A semisinusoidal wave load with a frequency of $1 \mathrm{~Hz}$ with no rest period was applied to represent the loading conditions experienced by a pavement layer under vehicular loading.

It should be pointed out that only the cyclic load is allowed to be input in the DDS-70 test system, and the magnitude of obtained cyclic stress depends on the stiffness of test specimen. The greater stiffness results in larger cyclic stress. That is, the same magnitude of cyclic load applied to different specimens would result in different magnitudes of cyclic stress. According to the SL237-032, multistage loading method was adopted for $E_{d}$ test, and ten dynamic deviator loads of $15,30,45,60,75,90,105,120,135$, and $150 \mathrm{~N}$ were applied in sequence for each specimen, as presented in Table 2 . For each sequence, 10 load cycles were applied and the cyclic stress and the vertical displacement were measured and used to determine the elastic modulus. For the PPS test, single-stage loading method was adopted, and four different deviator loads of 90, 120, 150, and $180 \mathrm{~N}$ were applied. Each specimen for PPS test was subjected to a prescribed deviatoric load level controlled by an internal load cell for 5000 cycles.

\section{Results and Discussion}

4.1. Dynamic Elastic Modulus. The dynamic elastic modulus is defined as the ratio of cyclic deviator stress to elastic strain. Figure 1 presents the relationship between dynamic elastic modulus and deviator stress at various moisture contents for specimens compacted at $90 \%, 93 \%$, and $96 \%$ of MDD, respectively. The dynamic elastic modulus decreases nonlinearly with an increase in the cyclic deviator stress. The significant effect of change in the postcompaction moisture content on the dynamic elastic modulus is also evident as shown in the figure. For tested specimens with different degrees of compaction, an increase in the moisture content that corresponded to decrease of matric suction resulted in considerable reduction in the dynamic elastic modulus. This behavior could be attributed to the fact that an increase in moisture content lubricates the grains and weakens the soil fabric, which in turn leads to an increased vulnerability to deformation, as shown in Figure 2. The elastic strain increases with an increase in the moisture content under the same deviator stress.

It is further observed that the dynamic elastic modulus exhibits a higher sensitivity to the moisture contents at lower deviator stress level. That is, at lower deviator stress level, the dynamic elastic modulus of the specimen decreases at a higher rate as the moisture content increases from $12 \%$ to $27 \%$, compared to that at higher deviator stress level. In addition, the typical stress-strain curves shown in Figure 2 at different moisture contents exhibit obvious nonlinear behavior, which can usually be characterized by the hyperbolic model [29], as shown in

$$
\sigma_{d}=\frac{\varepsilon_{d}}{1 / E_{d 0}+\varepsilon_{d} / \sigma_{d y}},
$$

where $E_{d 0}$ is the initial elastic modulus (tangent of the hyperbolic curve at the origin) and $\sigma_{d y}$ is the ultimate deviator stress (2 times the limit shear strength of specimen). The values of $1 / E_{d 0}$ and $1 / \sigma_{d y}$ can be obtained from the intercept and the slope of the measured $1 / E_{d}-\varepsilon_{d}$ linear curve.

It is stated that the values of $E_{d 0}$ and $\sigma_{d y}$ depend on the initial state of sample such as the applied confining stress, moisture content, and dry density, and $E_{d 0}, \sigma_{d y}$ can be used as useful index for normalizing the relationships between modulus and strain for soils with various moisture contents and compaction degrees. Figure 3 presents the relationship between the normalized elastic modulus $E_{d} / E_{d 0}$ and the normalized elastic strain $\varepsilon_{e} / \varepsilon_{r}$ for all the tested specimens, 


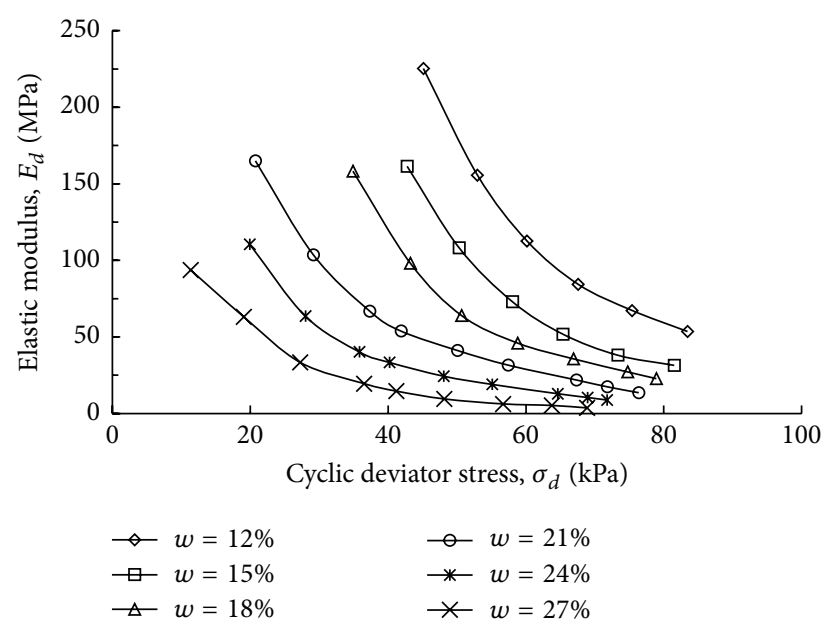

(a)

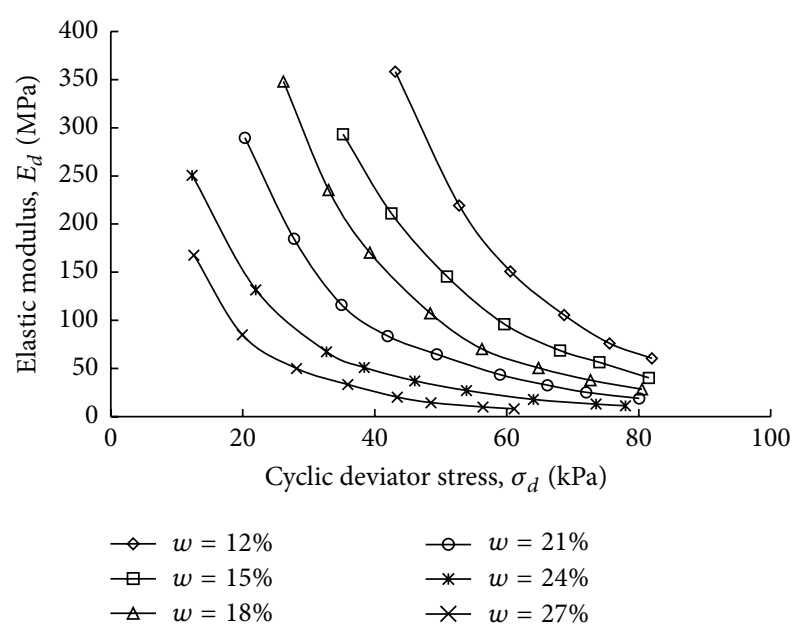

(b)

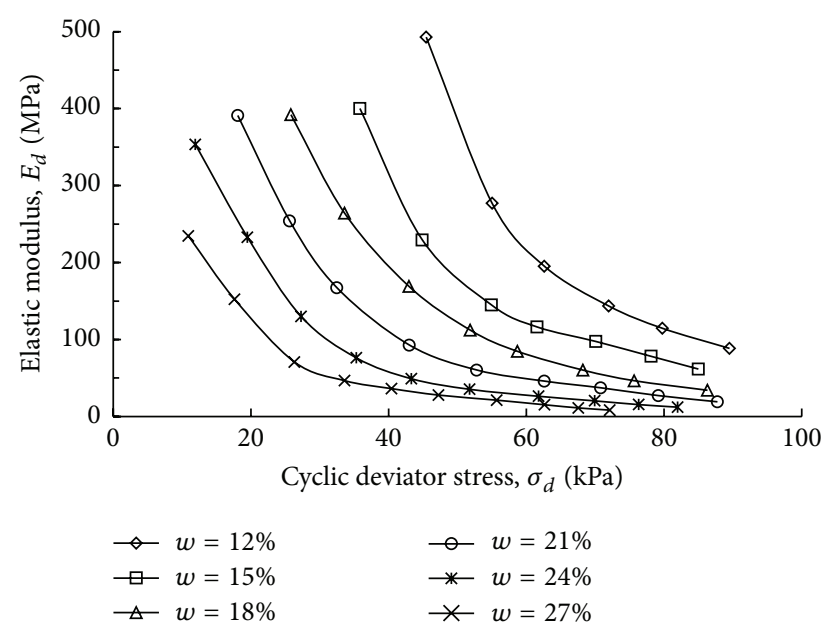

(c)

FIGURE 1: Variation of dynamic elastic modulus with deviator stress at various moisture contents for different degrees of compaction: (a) $k=90 \%$; (b) $k=93 \%$; (c) $k=96 \%$.

where $\varepsilon_{r}=\sigma_{d y} / E_{d 0}$ was defined as the reference strain [29]. Interestingly, a unique relationship between $E_{d} / E_{d 0}$ and $\left(\sigma_{d} / E_{d}\right) /\left(\sigma_{d y} / E_{d 0}\right)$ is obtained, within a large range of moisture contents (12-27\%) and various compaction degrees (90-96\%). A regression analysis gives the following simple equation with a correlation coefficient $R^{2}$ of 0.99 :

$$
\frac{E_{d}}{E_{d 0}}=0.48\left[\frac{\left(\sigma_{d} / E_{d}\right)}{\left(\sigma_{d y} / E_{d 0}\right)}\right]^{-0.678}
$$

Figure 4 illustrates the variation of normalized initial elastic modulus $E_{d 0} /\left(\mathrm{Pa} \times 10^{3}\right)$ with moisture content and degree of compaction, and Figure 5 shows the trend of normalized ultimate deviator stress $\sigma_{d y} / \mathrm{Pa}$ with moisture content and degree of compaction. As can be seen, both $E_{d 0} /\left(\mathrm{Pa} \times 10^{3}\right)$ and $\sigma_{d y} / \mathrm{Pa}$ decrease with an increase of moisture content and increase with an increase of degree of compaction. Furthermore, with the moisture content increasing, the magnitude of changes in $E_{d 0} /\left(\mathrm{Pa} \times 10^{3}\right)$ and $\sigma_{d y} / \mathrm{Pa}$ decreases. Based on the described properties of
$E_{d 0} /\left(\mathrm{Pa} \times 10^{3}\right)$ and $\sigma_{d y} / \mathrm{Pa}$, the following regression-based empirical models for $E_{d 0}$ and $\sigma_{d y}$ behavior of compacted subgrade are proposed:

$$
\begin{aligned}
E_{d 0} /\left(\mathrm{Pa} \times 10^{3}\right) & =\alpha_{1} w^{\alpha_{2}} k^{\alpha_{3}}, \\
\sigma_{d y} / \mathrm{Pa} & =\beta_{1} w^{\beta_{2}} k^{\beta_{3}},
\end{aligned}
$$

where $\mathrm{Pa}$ is the standard atmospheric pressure, $w$ is moisture content, $k$ is degree of compaction, and $\alpha_{1}, \alpha_{2}$, and $\alpha_{3}$ and $\beta_{1}$, $\beta_{2}$, and $\beta_{3}$ are regression parameters.

The regression parameters for the model presented in (3) were determined by least square curve fitting on the measured $E_{d 0}$ and $\sigma_{d y}$. The test data points obtained from six moisture contents and three degrees of compaction were used for this statistical analysis. The solver function in Microsoft Excel was used for the proposed model parameters optimization which was set up to minimize the sum of the squared errors between the measured value and the value predicted by the model. The coefficient of determination $R^{2}$ was also calculated to evaluate the goodness of model 


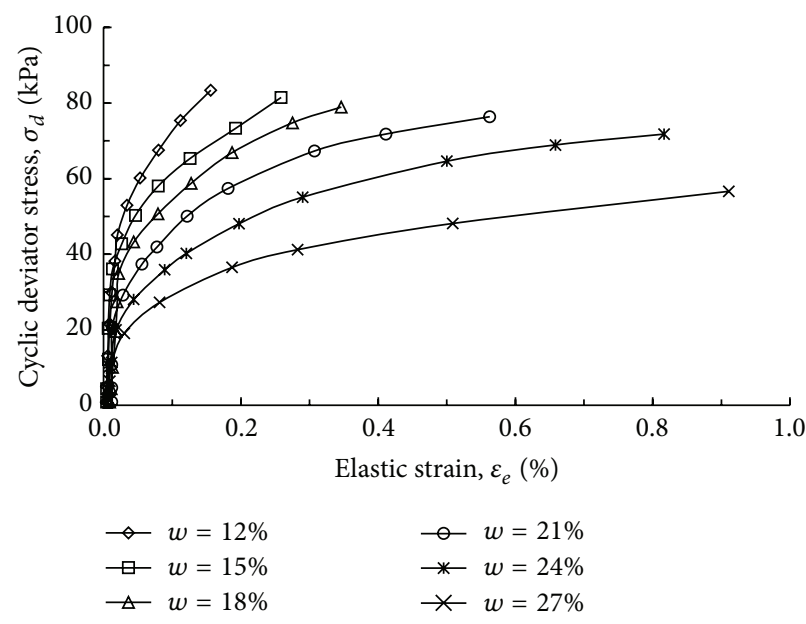

(a)

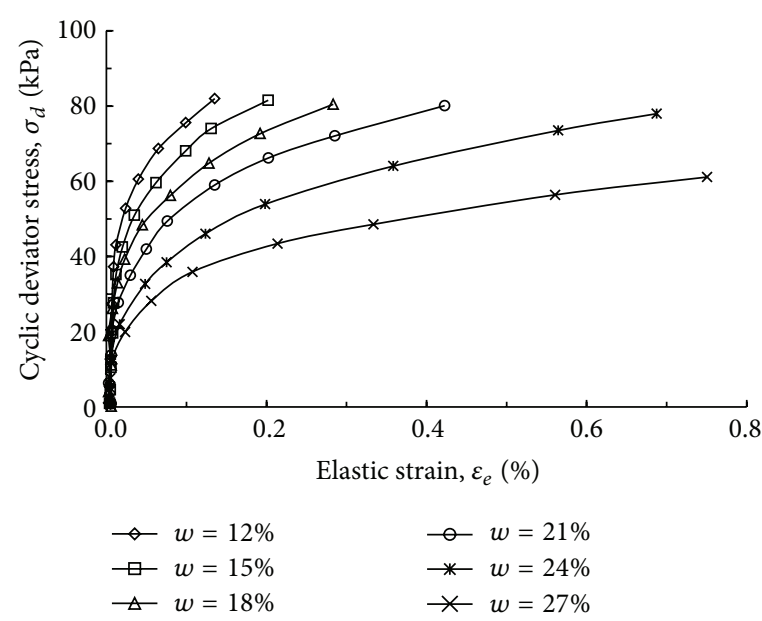

(b)

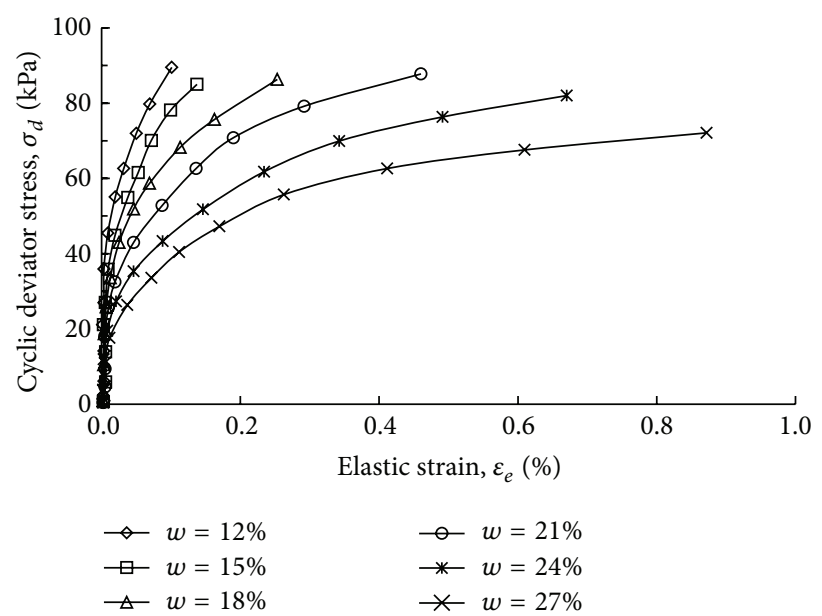

(c)

FIGURE 2: Relationship between deviator stress and elastic strain at various moisture contents for different degrees of compaction: (a) $k=90 \%$; (b) $k=93 \%$; (c) $k=96 \%$.

fitting at all the compaction degrees. Figure 4 presents the relationships between measured data and predicted result using the model with the parameters determined from the optimization procedure, and the calibrated parameters of the models and the $R^{2}$ values are also presented in the figure. It is seen that the coefficients of determination for $E_{d 0} /(\mathrm{Pa} \times$ $10^{3}$ ) and $\sigma_{d y} / \mathrm{Pa}$ curves are 0.99 and 1.00 , respectively, which indicate that the proposed models accurately capture the trends of measured $E_{d 0} /\left(\mathrm{Pa} \times 10^{3}\right)$ and $\sigma_{d y} / \mathrm{Pa}$ versus moisture contents at various degrees of compaction.

Combining (2) and (3), an empirical relationship between dynamic elastic modulus $E_{d}$ and cyclic deviator stress $\sigma_{d}$ is developed that incorporates density and moisture content variations. That is, the elastic modulus $E_{d}$ of subgrade at inservice state with different moisture contents and degrees of compaction can be predicted as the applied cyclic deviator stress and confining stress are available.

4.2. Plastic Permanent Deformation. A series of cyclic load tests were performed at different moisture content levels with varying degrees of compaction and at different deviator stress levels. As an example, at a constant cyclic deviator load of $150 \mathrm{~N}$, the measured accumulated permanent strains as a function of number of load applications for a predetermined range of moisture contents are presented in Figure 5. This figure shows a considerable influence of moisture content on the permanent strain response of the compacted lateritic soil. The permanent strain increases as the moisture content increases and the increase is more pronounced at high moisture content. With increasing in moisture content, the type of permanent strain response to cyclic loading changes from stable state to unstable state. That is, at low moisture content, the specimen exhibits a long-term steady state with no further accumulation of permanent strain and entirely resilient response, while at high moisture content the specimens have achieved progressive failure or collapse state after a finite number of load cycles. Furthermore, results in Figure 5 show that a higher degree of compaction yields a lower accumulated permanent strain and a more stable response; that is, the failure or collapse state achieved in 


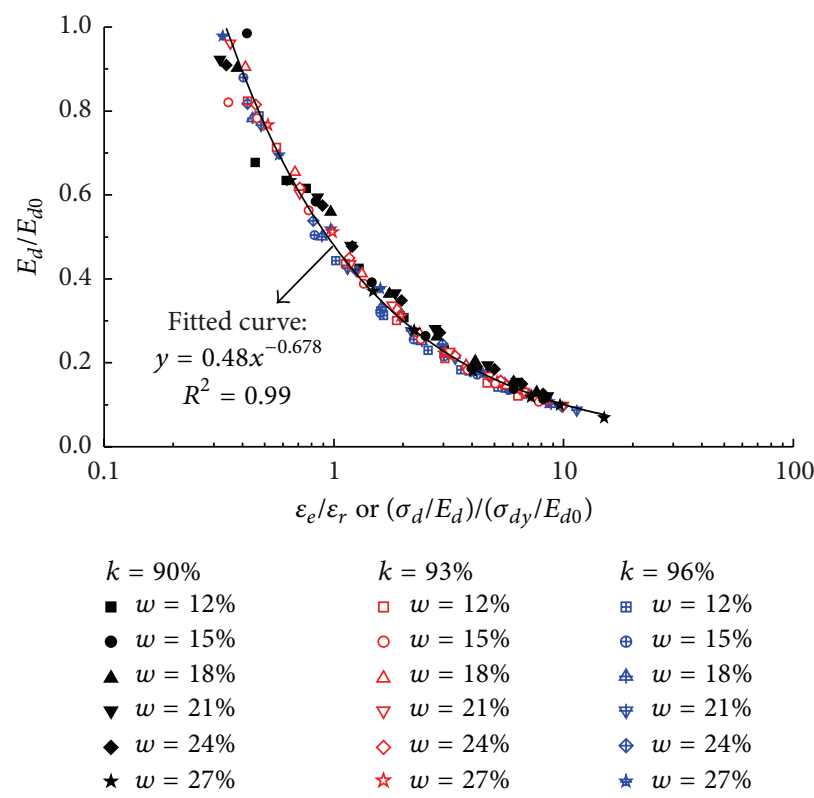

Figure 3: Correlation of $E_{d} / E_{d 0}$ with $\left(\sigma_{d} / E_{d}\right) /\left(\sigma_{d y} / E_{d 0}\right)$.

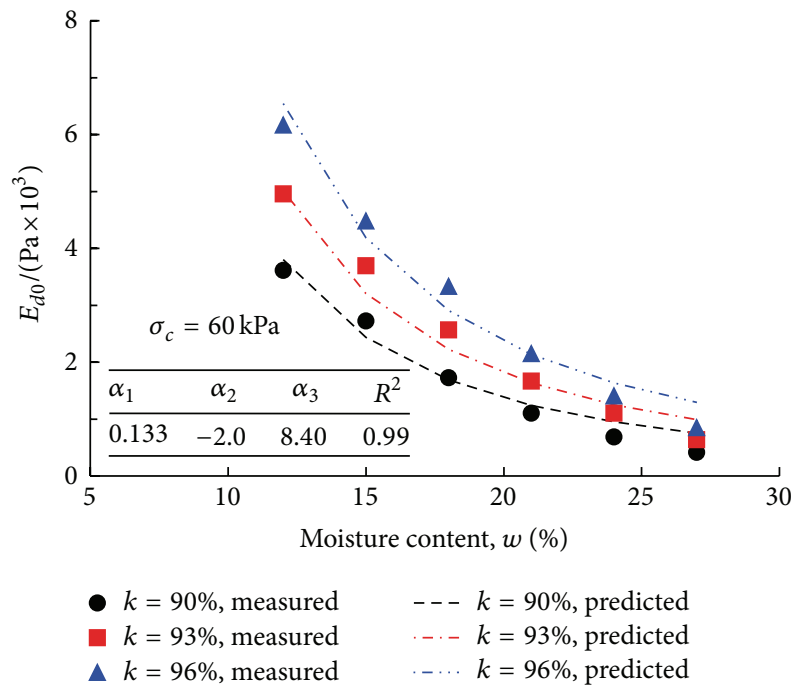

(a)

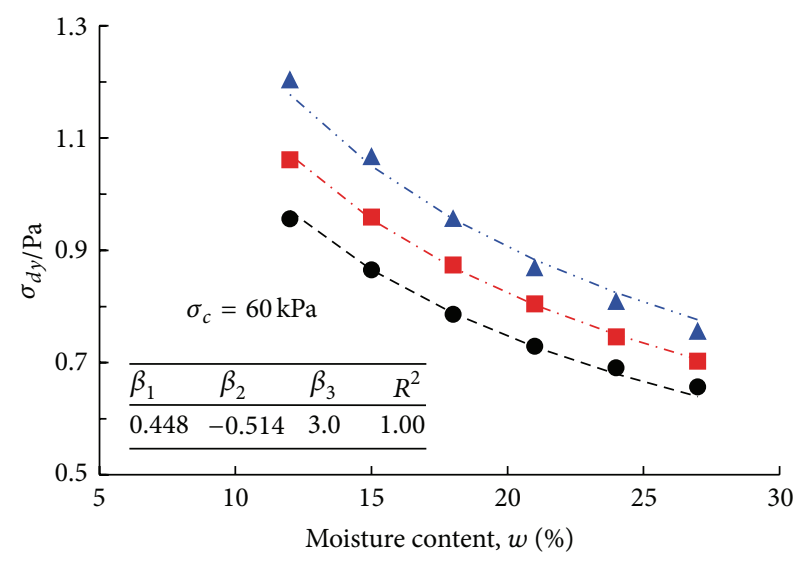

- $k=90 \%$, measured $\quad---k=90 \%$, predicted

- $k=93 \%$, measured … $k=93 \%$, predicted

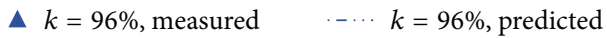

(b)

Figure 4: Comparison of lab-measured results and model-predicted values versus moisture content for various degrees of compaction: (a) $E_{d 0} /\left(\mathrm{Pa} \times 10^{3}\right) ;(\mathrm{b}) \sigma_{d y} / \mathrm{Pa}$.

the specimens compacted at $90 \%$ and $93 \%$ of MDD is not observed in the specimens with $96 \%$ of MDD.

Figure 6 shows the variation of permanent strain after 5000 cycles with cyclic deviator stress for different moisture contents and degrees of compaction. It is observed that the higher cyclic deviator stress results in the higher permanent strain at the same moisture content. As increasing in moisture content, especially increases from 18\% (OMC), the accumulation of permanent strain exhibits more sensitivity to the cyclic deviator stress, and higher magnitudes of change in permanent strain are observed for specimens with higher moisture content. Quite similar trends are observed for specimens with three different degrees of compaction. This is due to a decrease in soil matric suction with an increase of moisture content, thus reducing the effective stress, which in turn decreases the resistance to withstand accumulation of permanent deformation.

Figure 7 shows the associated permanent strain rate versus accumulative permanent strain from a series of cyclic tests with combination of various moisture contents and deviator stress. For example, the test condition with moisture content of $12 \%$ and the deviator stress of $45 \mathrm{kPa}$ is expressed as $12 \%-45$ in the legend. It is observed that the permanent strain rate decreases rapidly for the cases with low moisture content 


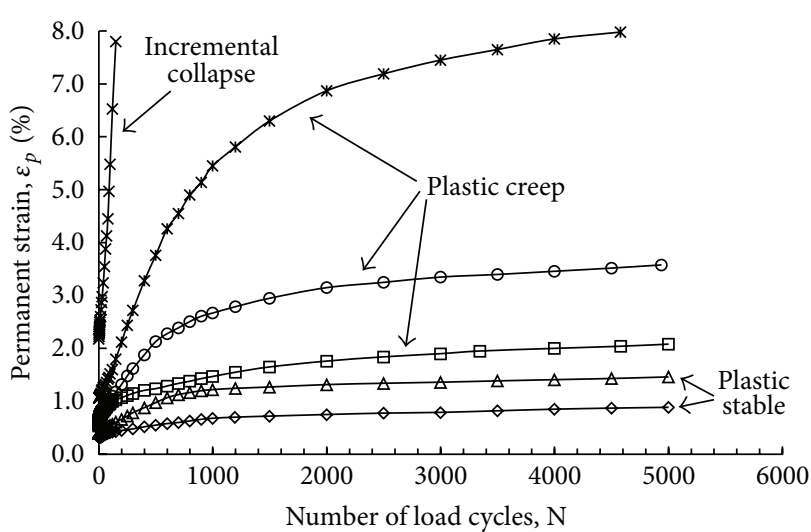

$$
\begin{aligned}
& \smile w=12 \% \\
& \square w=15 \% \\
& \square w=18 \%
\end{aligned}
$$

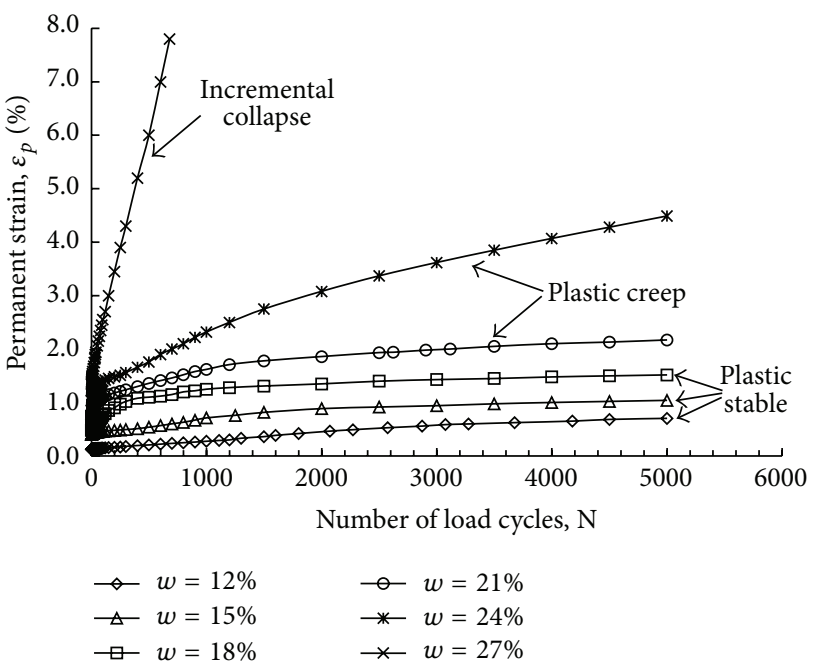

(b)

(a)

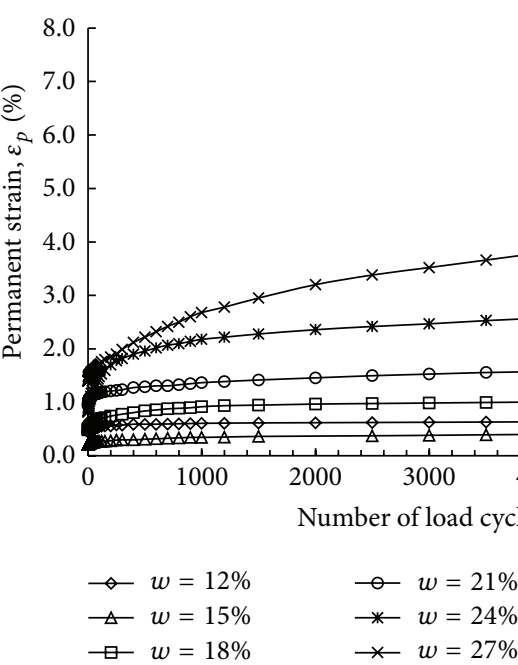

(c)

FIGURE 5: Permanent strain under a cyclic deviator load of $150 \mathrm{~N}$ for various moisture contents and different degrees of compaction: (a) $k=90 \%$; (b) $k=93 \%$; (c) $k=96 \%$.

and low deviator stress. In contrast, for the cases with high moisture content and high deviator stress, the permanent strain rate decreases very slowly or keeps constant, which causes progressive accumulation of permanent strain and may eventually lead to unstable or failure state. Furthermore, both permanent strain rate and permanent strain decrease with the increase of degree of compaction under an identical condition, and more curves of permanent strain response with stable state are observed for the case with high degree of compaction.

The evolution of permanent strain of fine grained subgrade soils with load cycles is complex and dependent on the stress level, moisture content, and degree of compaction. The shakedown concept, firstly introduced in pavement engineering by Sharp and Booker [30], is used to characterize the permanent deformation behavior of compacted lateritic soil under cyclic loading. According to Werkmeister et al. [31], the concept maintains that the materials response under repeated loading can be classified into four different categories: elastic shakedown, plastic shakedown, plastic creep, and incremental collapse:

(1) Elastic shakedown, where the applied cyclic stress is sufficiently small compared to the strength of the material and the material response is purely elastic.

(2) Plastic shakedown, where the cumulative permanent strain rate decreases rapidly until it reaches a state of equilibrium and the material gradually achieves a long-term steady state response.

(3) Plastic creep shakedown, where the permanent strain rate is decreasing and slowly accumulative permanent strain is observed; however, the material plastic response neither ceases nor leads to a sudden collapse.

(4) Incremental collapse, where the applied cyclic stress is relatively large to cause the material to reach and 


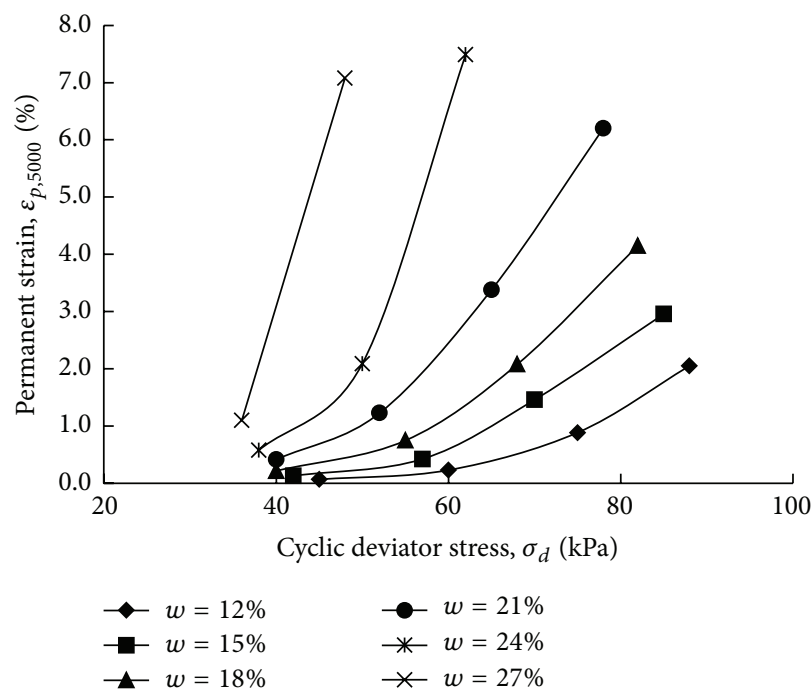

(a)

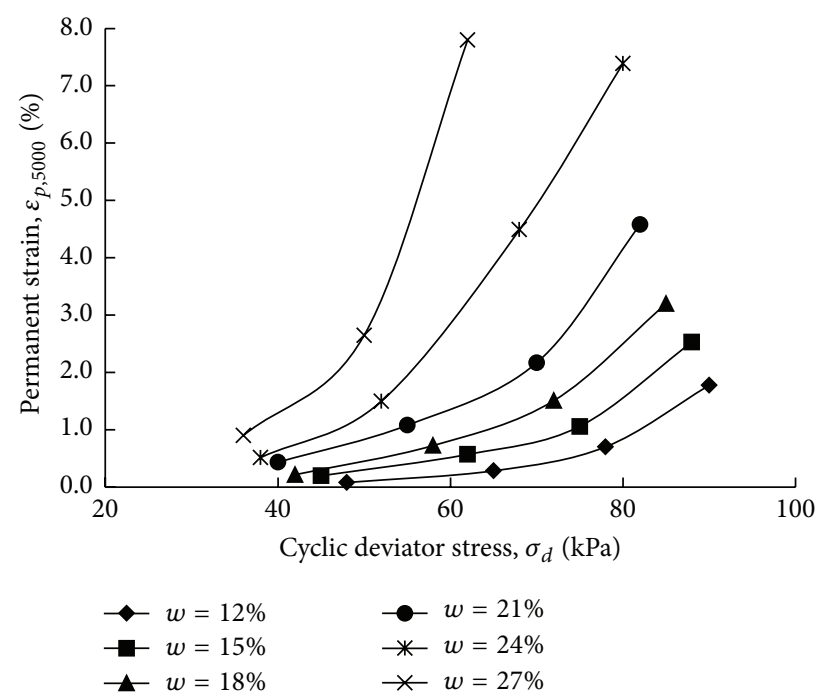

(b)

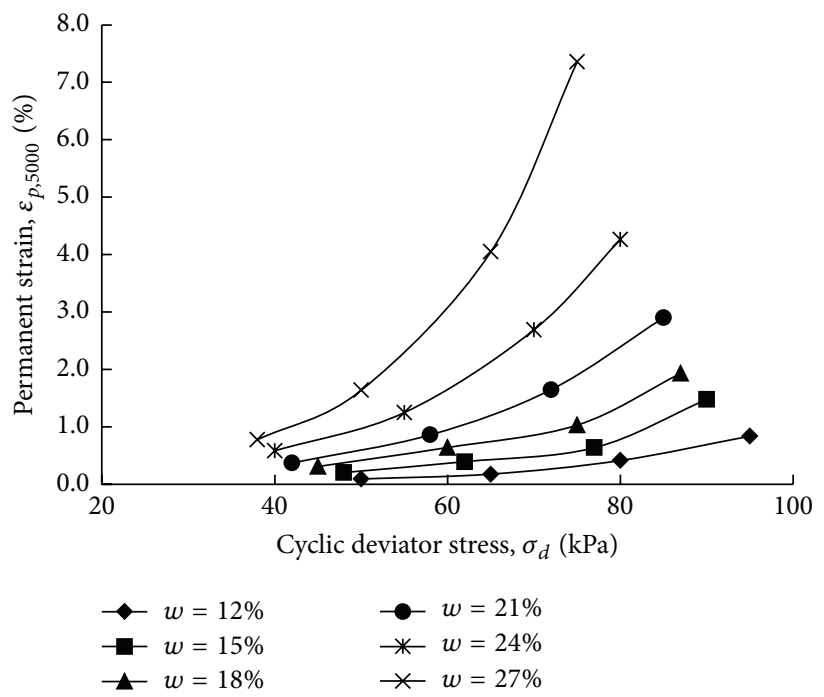

(c)

Figure 6: Relationships between permanent strain after 5000 cycles and cyclic deviator stress for different moisture contents and degrees of compaction: (a) $k=90 \%$; (b) $k=93 \%$; (c) $k=96 \%$.

exceed the yield stress and the accumulated plastic strains then increase rapidly with failure occurring in a small number of load cycles.

Based on the above-stated definitions of different deformation stages and the shapes or slopes of the measured permanent strain curves, three states of permanent strain accumulation, plastic stable, plastic creep, and incremental collapse, are observed and labeled in Figures 5 and 7 . All test specimens experience some permanent strain; thus none of results shows behavior in the elastic shakedown range.

By considering the shakedown concept, the classification assumes the existence of certain limiting values which define the stress states at which the type of permanent strain response changes. In particular, for design purposes, this implies that the maximum cyclic stress level, which is associated with a resilient response after slight plastic strain accumulates in the initial cycles, should be determined and subsequently not be exceeded, if uncontrolled permanent deformations are to be prevented. The maximum cyclic stress is defined as the critical dynamic stress $\sigma_{d c}$, below which permanent deformations are small and shaken down and above which repeated applications of a load cause large permanent deformations attributed to unstable state.

The critical dynamic stress distinguishing stable from unstable state is the key design parameter and can be estimated from the maximum stress in the plastic shakedown stage. Figure 8 presents the estimated critical dynamic stress as a function of moisture content for various degrees of compaction. It can be clearly seen that the critical dynamic stress decreases with an increase in moisture content, and the magnitude of decrease in $\sigma_{d c}$ is higher at the wet side of OMC than that at dry side of OMC. With increase of 


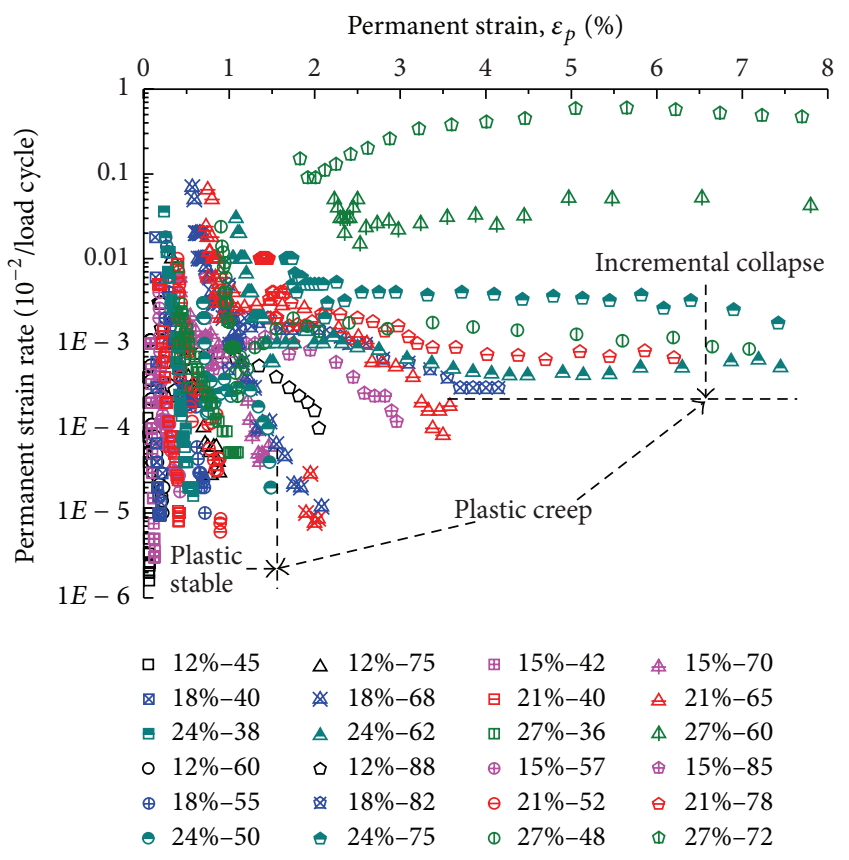

(a)

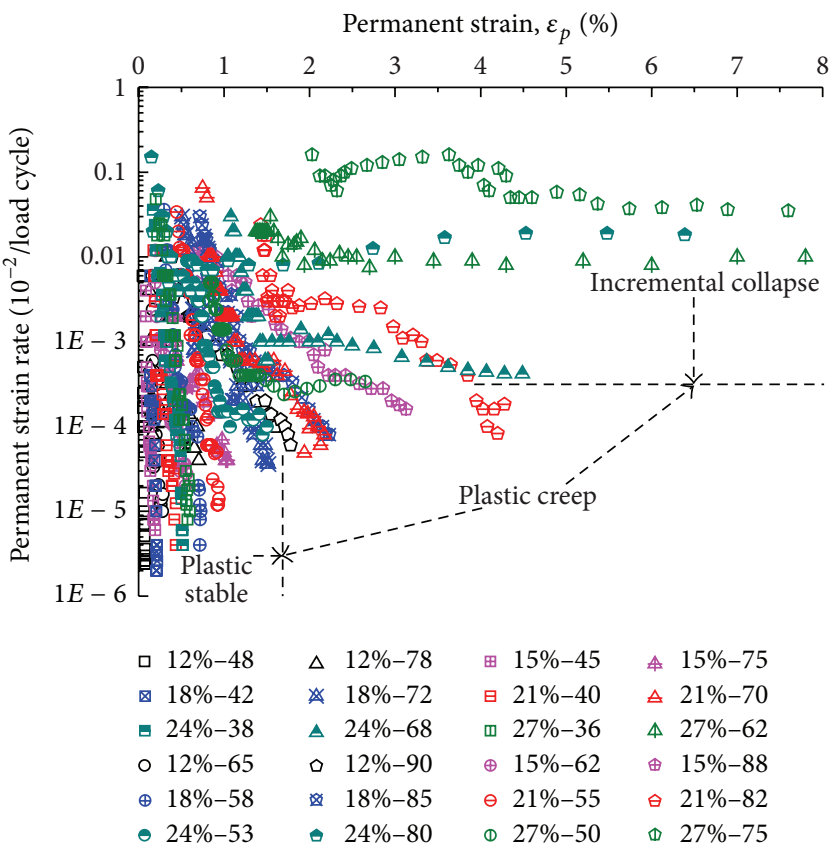

(b)

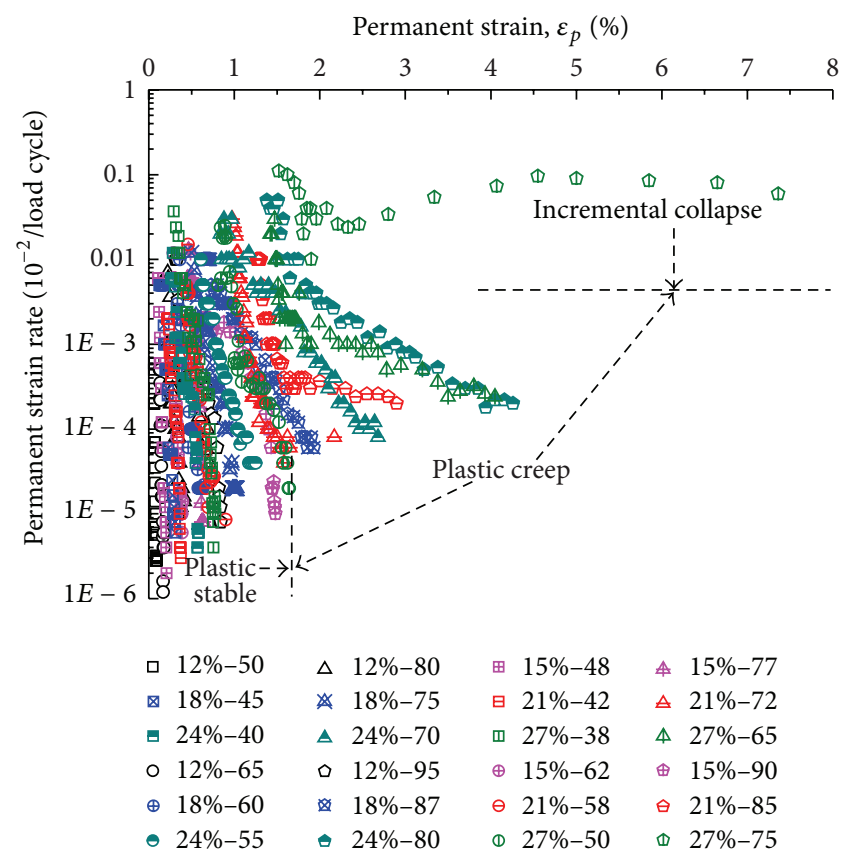

(c)

FIGURE 7: Relationship between permanent strain rate (log scale) and permanent strain under combination of various moisture contents and deviator stress values for different degrees of compaction: (a) $k=90 \%$; (b) $k=93 \%$; (c) $k=96 \%$.

degree of compaction the critical dynamic stress increases, and higher magnitude of increase in $\sigma_{d c}$ is observed as the degree of compaction changes from $90 \%$ to $93 \%$ compared to that of the case with changing from $93 \%$ to $96 \%$. Moreover, the presented envelope curves of $\sigma_{d c}$ moisture for different compaction degrees can provide reference for the pavement design, for assuring that the compacted subgrade soils should preferably not undergo cyclic stress level higher than the critical dynamic stress, in which condition the permanent strain accumulation would terminate after a sufficient number of loading cycles and only minor permanent deformation would take place. 


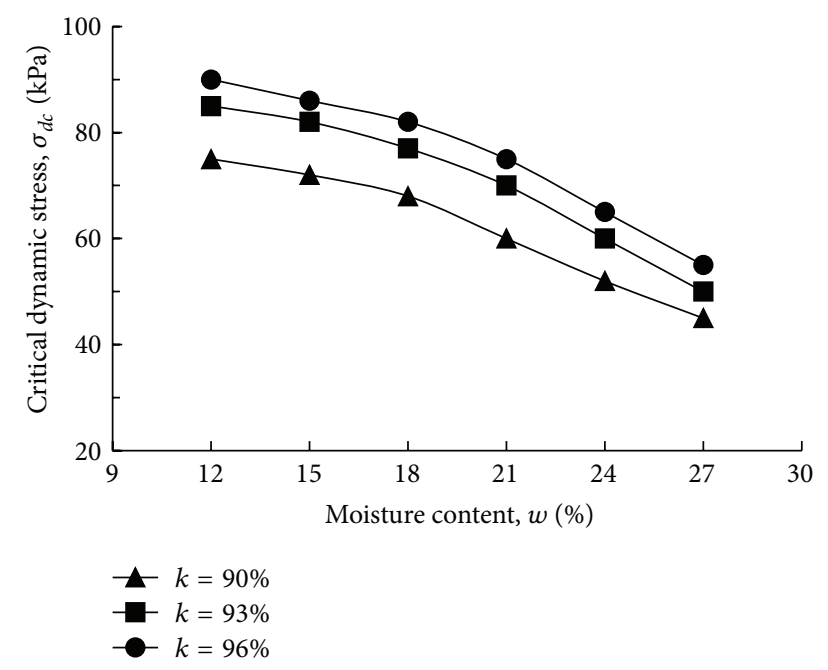

FIgURE 8: Critical dynamic stress versus moisture content for various degrees of compaction.

\section{Conclusions}

Both elastic (resilient) deformation and plastic permanent deformation behavior of compacted lateritic soil were investigated using a series of repeated loading tests. The tests were conducted at different moisture contents with varying dry densities and at different cyclic stress levels to simulate the seasonal environmental and traffic conditions in reality. The following conclusions are drawn in view of the results:

(1) The elastic stiffness $\left(E_{d}\right)$ decreases with increased moisture content and cyclic deviator stress $\left(\sigma_{d}\right)$ and increases with increased degree of compaction. An empirical relationship between dynamic elastic modulus $E_{d}$ and applied cyclic stress $\sigma_{d}$ is developed that incorporates variations of density and postcompaction moisture content.

(2) The plastic permanent strain decreases due to drying and increases due to wetting. With increasing in moisture content, the type of permanent strain accumulation response changes from plastic stable (shakedown) to plastic creep and eventually to incremental collapse.

(3) With an increase in moisture content, the higher magnitude of decrease in critical dynamic stress $\sigma_{d c}$ is observed at the wet side of OMC compared to the corresponding changes at dry side of OMC. Moreover, the envelope curves of $\sigma_{d c}$ moisture for different degrees of compaction are presented, which may be useful for improving the pavement design to incorporate the postcompaction moisture content variation due to seasonal environmental effect.

\section{Competing Interests}

The authors declare that there is no conflict of interests regarding the publication of this paper.

\section{Acknowledgments}

The authors acknowledge the National Natural Science Foundation of China (51208517, U1134207, and 51478054), Project funded by China Postdoctoral Science Foundation (no. 2013M530360), and State Engineering Laboratory of Highway Maintenance Technology, Changsha University of Science \& Technology (kf150103). The authors are also grateful to Mr. Tianqi Qiu at Tsinghua University and Mr. Xiangtian Yang at Tongji University for their help in the repeated loading triaxial tests.

\section{References}

[1] G. B. Thadkamalla and K. P. George, "Characterization of subgrade soils at simulated field moisture," Transportation Research Record: Journal of Transportation Research Record, vol. 1481, pp. 21-27, 1995.

[2] J. Uzan, "Characterization of clayey subgrade materials for mechanistic design of flexible pavements," Journal of Transportation Research Recor, vol. 1629, pp. 189-196, 1998.

[3] H. P. Thang, C. Matthew, J. W. David et al., "Case study of seasonal variation in the subgrade and subbase layers of highway US 20," Report CTRE Project 04-172, IHRN Project TR-516, Iowa State University, Ames, Iowa, USA, 2008.

[4] Q. Nguyen, D. G. Fredlund, L. Samarasekera, and B. L. Marjerison, "Seasonal pattern of matric suctions in highway subgrades," Canadian Geotechnical Journal, vol. 47, no. 3, pp. 267-280, 2010.

[5] J. H. Zhang, Q. P. Jiang, Y. Q. Zhang, L. L. Dai, and H. X. Wu, "Nondestructive measurement of water content and moisture migration of unsaturated red clays in South China," Advances in Materials Science and Engineering, vol. 2015, Article ID 542538, 7 pages, 2015.

[6] E. C. Drumm, J. S. Reeves, M. R. Madgett, and W. D. Trolinger, "Subgrade resilient modulus correction for saturation effects," Journal of Geotechnical Engineering, vol. 123, no. 7, pp. 663-670, 1997.

[7] S.-R. Yang, W.-H. Huang, and Y.-T. Tai, "Variation of resilient modulus with soil suction for compacted subgrade soils," Transportation Research Record, no. 1913, pp. 99-106, 2005.

[8] N. Khoury, R. Brooks, S. Y. Boeni, and D. Yada, "Variation of resilient modulus, strength, and modulus of elasticity of stabilized soils with postcompaction moisture contents," Journal of Materials in Civil Engineering, vol. 25, no. 2, pp. 160-166, 2013.

[9] M. Y. Abu-Farsakh, A. Mehrotra, L. Mohammad, and K. Gaspard, "Incorporating the effect of moisture variation on resilient modulus for unsaturated fine-grained subgrade soils," Transportation Research Board, vol. 2510, pp. 44-53, 2015.

[10] J. H. Charman, Laterite in Road Pavements, vol. 47 of Special Publication, Construction Industry Research and Information Association (CIRCA), London, UK, 1988.

[11] Q. T. Bi, G. P. Jiang, and S. Y. Ding, "Water content influence on the shearing strength of red clay," Earth and Environment, vol. 33, no. 3, pp. 144-147, 2005 (Chinese).

[12] Y. H. Wang, Q. X. Zhang, P. C. Tian, and S. Q. Liang, "Effects of water content variation on the deformation and shear strength of laterite clay," Geotechnical Investigation \& Surveying, vol. 37, no. 7, pp. 10-13, 2009 (Chinese).

[13] D. W. Zhang, S. Y. Liu, and T. Zhang, "Water content and modulus relationship of a compacted unsaturated soil," Journal 
of Southeast University (English Edition), vol. 28, no. 2, pp. 209214, 2012 (Chinese).

[14] Y. Huang, Z. L. Zhang, K. S. Jin, and P. Liu, "Influence of variation of moisture conditions on characteristics of Yunnan laterite," Journal of Hohai University, vol. 241, no. 6, pp. 518-524, 2013 (Chinese).

[15] R. Zhao, S. Y. Zuo, S. Wang, S. Li, and C. Huang, "Experiment and mechanism analysis of water contents on triaxial shear strength of the remodeled red clay of Guiyang," Hydrogeology \& Engineering Geology, vol. 42, no. 5, pp. 90-95, 2015.

[16] M. Fall, J.-P. Tisot, and I. K. Cisse, "Undrained behaviour of compacted gravel lateritic soils from western Senegal under monotonic and cyclic triaxial loading," Engineering Geology, vol. 47, no. 1-2, pp. 71-87, 1997.

[17] F. Samb, M. Fall, Y. Berthaud, and M. Bâ, "Resilient modulus of compacted lateritic soils from senegal at OPM conditions," Geomaterials, vol. 3, no. 4, pp. 165-171, 2013.

[18] A. B. Parreira and R. F. Gonçalves, “The influence of moisture content and soil suction on the resilient modulus of a lateritic subgrade soil," in GeoEng-An International Conference on Geotechnical \& Geological Engineering, Melbourne, Australia, Technomic, Lancaster, Pa, USA, 2000.

[19] K. Mu, A. G. Guo, W. Bai, Z. L. Sun, and M. Zang, "Experimental study on dynamic properties of red clay in Guangxi under cyclic loading," China Earthquake Engineering Journal, vol. 37, no. 2, pp. 487-493, 2015 (Chinese).

[20] H.-R. Liao, L.-S. Tang, Z.-X. Liu, and Q.-H. Zhang, "Analysis of critical stress level of subgrade red clay under cyclic loading," Rock and Soil Mechanics, vol. 30, no. 3, pp. 587-594, 2009 (Chinese).

[21] X.-H. Liu, G.-L. Yang, and W. Fang, "Critical dynamic stress of red clay and replacement thickness of ballastless track cutting bed of high-speed railways," Chinese Journal of Geotechnical Engineering, vol. 33, no. 3, pp. 348-353, 2011 (Chinese).

[22] J. H. Zhang, Z. Y. Yin, and J. L. Zheng, "Research on critical stress level of Shakedown of red clay in southern hot and humid areas," Journal of Central South University (Science and Technology), vol. 45, no. 4, pp. 1288-1292, 2014 (Chinese).

[23] R. D. Barksdale, "Laboratory evaluation of rutting in base course materials," in Proceedings of the 3rd International Conference on the Structural Design of Asphalt Pavements, pp. 161-174, London, UK, 1972.

[24] B. Vuong, "Influence of density and moisture content on dynamic stress-strain behaviour of a low plasticity crushed rock," Road and Transport Research, vol. 1, no. 2, pp. 88-100, 1992.

[25] A. A. Van Niekerk, Mechanical behavior and performance of granular bases and sub-bases in pavements [Ph.D. thesis], Delft University of Technology, Delft, Netherlands, 2002.

[26] M. Taamneh and R. Y. Liang, "Long-term field monitoring of moisture variations under asphalt pavement with different drainable base materials," in Proceedings of the Paving Materials and Pavement Analysis (GeoShanghai '10), Geotechnical Special Publication no. 203, pp. 453-459, Shanghai, China, June 2010.

[27] J. Mendes, Assessment of the impact of climate change on an instrumented embankment: an unsaturated soil mechanics approach [Ph.D. thesis], Durham University, Durham, UK, 2011.

[28] Specification of Soil Test. Industrial Standard of the People's Republic of China, SL237-1999, Nanjing Hydraulic Research Institute, Nanjing, China, 1999.
[29] B. O. Hardin and V. P. Drnevich, "Shear modulus and damping in soils: design equations and curves," Journal of the Soil Mechanics and Foundations Division, ASCE, vol. 98, no. 7, pp. 667-692, 1972.

[30] R. W. Sharp and J. R. Booker, "Shakedown of pavements under moving surface loads," Journal of Transportation Engineering, vol. 110, no. 1, pp. 1-14, 1984.

[31] S. Werkmeister, A. R. Dawson, and F. Wellner, "Permanent deformation behavior of granular materials," Road Materials and Pavement Design, vol. 6, no. 1, pp. 31-51, 2005. 

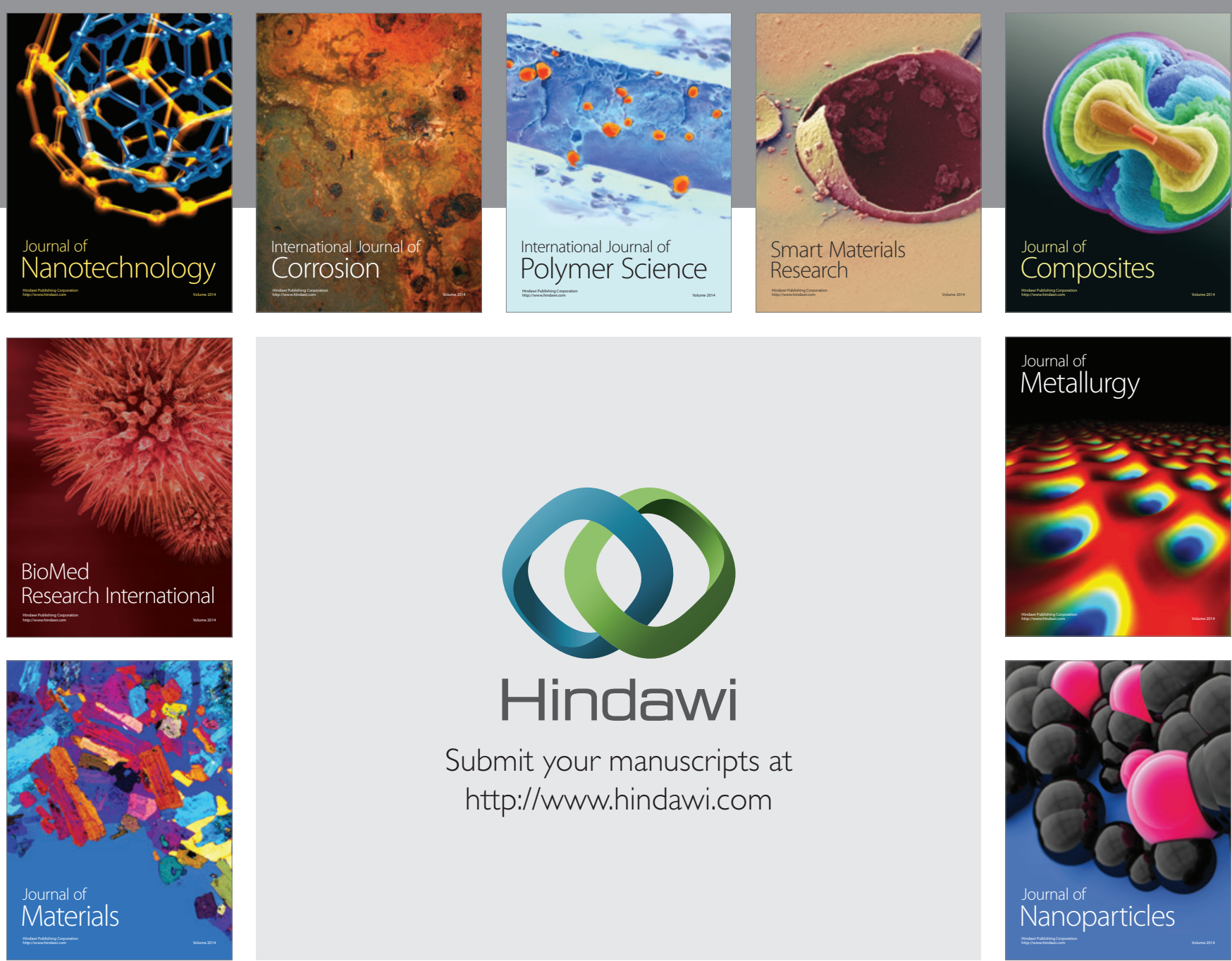

\section{Hindawi}

Submit your manuscripts at

http://www.hindawi.com

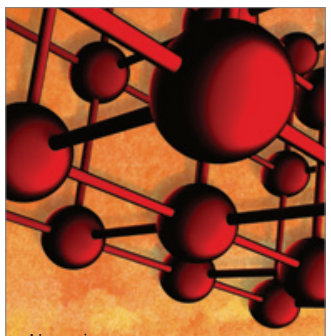

Materials Science and Engineering
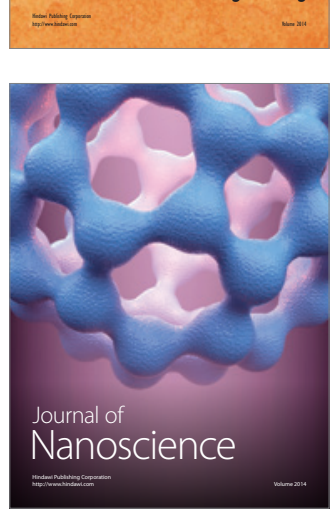
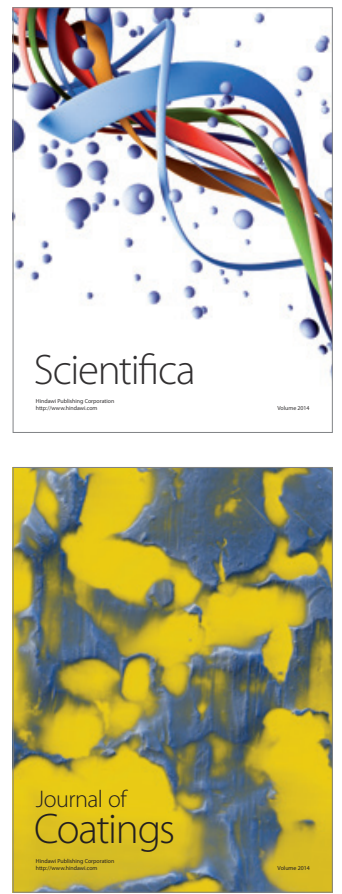
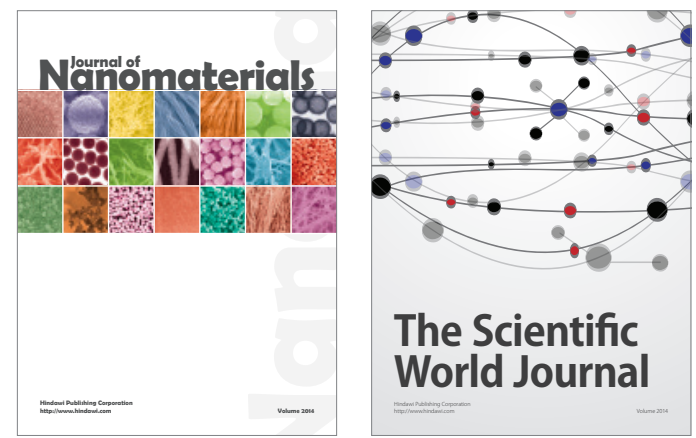

The Scientific World Journal
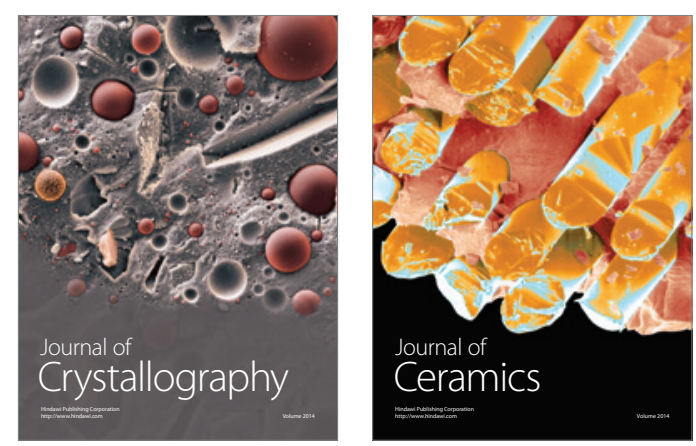
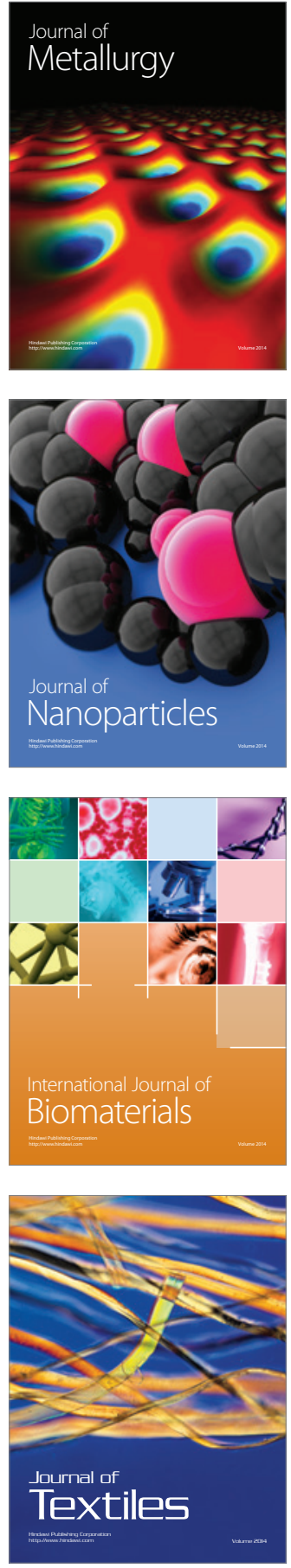